\title{
FURTHER ELECTROPHYSIOLOGICAL EVIDENCE FOR THE GABA-LIKE EFFECT OF DROPERIDOL IN THE PURKINJE CELLS OF THE CAT CEREBELLUM ${ }^{1}$
}

\author{
Shoji MARUYAMA and Tadashi KAWASAKI* \\ Department of Neurophysiology, Brain Research Institute, \\ Niigata University, Nitgata 951 , and \\ *Department of Pharmacology, Faculty of Medicine, Toyama Medical and \\ Pharmaceutical University, Toyama 930, Japan \\ Accepted July 22, 1976
}

In our previous paper we reported that droperidol, one of butyrophenones, acts by occupying GABA receptors and exerting a GABA-like effect on the postsynaptic membrane of GABA-operated synapses, while chlorpromazine, one of phenothiazines, apparently does not have such an action (1). The present work was an attempt to provide further evidence for a GABA-like effect of droperidol. We investigated the interaction between droperidol or chlorpromazine and imidazole acetic acid which is known to act on the same group of receptors as GABA (2-4), or glycine which is reported to depress the firing rate of Purkinje cells in the cat cerebellum $(5,6)$.

Experiments were carried out on 34 adult cats anesthetized with pentobarbital sodium (40 mg/ $\mathrm{kg}$, i.p.). The surgical procedures and recording and analysis of data were essentially the same as those in our previous experiment (1). Single units were recorded extracellularly from spontaneously firing Purkinje cells in the superficial folia of the cerebellar vermis and drugs were administered microiontophoretically at the site of recording through 3-, or 6-barreled micropipettes (with 2.5-7.5 $/ \mathrm{m}$ tip diameters). Drugs used were as follows: droperidol (7 mM, pH 4.2, tartaric acid; Janssen); chlorpromazine $\mathrm{HCl}(50 \mathrm{mM}$ in $150 \mathrm{mM}$ $\mathrm{NaCl}, \mathrm{pH} 5.4$; Merck); imidazole acetic acid (0.5 M, pH 3.2, NaOH; Sigma); glycine (1 M, pH 3.2, $\mathrm{HCl}$; Sigma); bicuculline ( $5 \mathrm{mM}$ in $165 \mathrm{mM} \mathrm{NaCl}, \mathrm{pH} 3.2, \mathrm{HCl}$; Pierce). All these drug solutions were ejected with a positive current and the ejection time was $10 \mathrm{sec}$. Extracellular action potentials were recorded on an audiotape for later processing by a PDP-12 computer.

All Purkinje cells recorded in the present experiments were sensitive to GABA ejected with 5-80 nA. First, interaction between droperidol and imidazole acetic acid (IAA) was examined in 22 Purkinje cells. IAA (more than $30 \mathrm{nA}$ ) and droperidol (more than $40 \mathrm{nA}$ ) depressed the spontaneous firing in 18 and 14 of 22 Purkinje cells, respectively; IAA in 4 cells and droperidol in 8 cells did not produce any significant action, or it was difficult to distinguish a possible depression due to IAA or droperidol from a spontaneous variation of the firing frequency. A comparison of the action of IAA and droperidol on the same cell

\footnotetext{
1 The subject of this work was presented at 6th International Congress of Pharmacology, Helsinki,
} Finland, July 20-25, 1975. 
revealed that IAA was slightly more effective than droperidol. Concurrent microiontophoresis of IAA and droperidol was tried with some ejecting currents, with which each of two drugs had little or slight direct depressant effect on the spontaneous firing, in 16 of 22 Purkinje cells. As shown in the first tracing of Fig. 1, prior iontophoresis of droperidol (30 $\mathrm{nA})$, which produced no direct depression by itself, enhanced a slight depressant effect of IAA ( $20 \mathrm{nA})$ in 14 of 16 cells; in 2 cells no synergism between IAA and droperidol occurred. Bicuculline ( $80 \mathrm{nA}$ ) almost completely blocked, or significantly reduced the depressant effect of IAA and droperidol in 5 of 6 cells (2nd tracing of Fig. 1).

Examination was then made of interaction between glycine and droperidol in 12 Purkinje

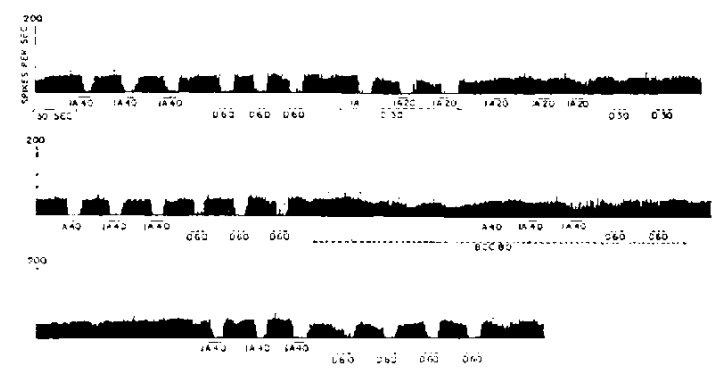

FIG. 1. Effects of IAA and droperidol, synergism between IAA and droperidol, and antagonism between IAA or droperidol and bicuculline on a spontaneously firing Purkinje cell. The microiontophoretic administration of IAA, droperidol, and bicuculline is indicated by horizontal lines, bars, and dots, together with the iontophoretic currents(nA). IAA: imidazole acetic cid; D: droperidol; BCC; bicuculline. Ordinate: spikes per sec; abscissa: time in sec.

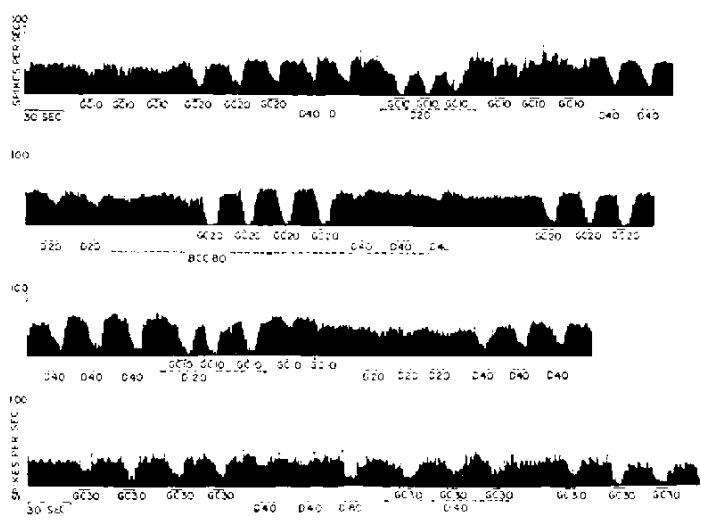

FIG. 2. Effects of glycine and droperidol, interaction between glycine and droperidol, and interaction between glycine or droperidol and bicuculline on spontaneously firing Purkinje cells. The first, second, and third tracings are the continuous records of the firing of a Purkinje cell, and the fourth tracing is the record of the firing of a different cell. The microiontophoretic administration of glycine, droperidol, and bicuculline is indicated by horizontal lines, bars, and dots respectively, together with the iontophoretic currents(nA). GC: glycine; $D$ : droperidol; BCC: bicuculine. Ordinate: spikes per sec; abscissa: time in sec. 
cells. Glycine (more than $20 \mathrm{nA}$ ) and droperidol depressed the spontaneous firing in 11 and 10 of 12 cells, respectively. In 9 of 10 cells which showed a clear depressant response to both glycine and droperidol, concurrent iontophoresis of two drugs was tried in the same manner as that for IAA and droperidol. As shown in the 1st tracing of Fig. 2, glycine, applied concurrently during the release of droperidol which had only a slight depressant effect, produced a more significant depressant effect than when given alone in 5 of 9 cells tested; in 4 cells, glycine produced the same depressant effect as before, as illustrated in the 4th tracing of Fig. 2. Bicuculline ( $80 \mathrm{nA}$ ) did not antagonize the depressant effect of glycine, but rather blocked the effect of droperidol in 7 of 8 cells tested; in one cell antagonism between glycine or droperidol and bicuculline was not clear, because bicuculline enhanced the firing rate.

Interaction between chlorpromazine and IAA or glycine was then examined. Prior iontophoresis of chlorpromazine, which caused no direct depression of firing, did not affect the depressant effect of IAA in all 8 Purkinje cells tested. In addition, chlorpromazine did not enhance or reduce the depressant effect of glycine applied concurrently during the release of chlorpromazine in all 5 cells tested (refer to reference 1)).

The present results demonstrate that IAA depresses the spontaneous firing of Purkinje cells, which are sensitive to GABA, and this depressant effect of IAA is enhanced by the concurrent application of droperidol, and that bicuculline antagonizes IAA and droperidol. As mentioned in the introduction, IAA is considered to act on receptors similar to the GABA-type receptors (2-4). Therefore, the present findings lend support to the conclusions drawn in our previous paper that droperidol produces a GABA-like effect on the GABA-operated, bicuculline-sensitive synapses.

The depressant effect of glycine was found to be enhanced in about half the number of Purkinje cells tested and to be unaffected in the remaining by the concurrent release of droperidol. In addition, depression produced by glycine was not blocked by the concurrent release of bicuculline in all cells tested. Thus the mechanism of the depressant action of glycine is apparently different from that of droperidol, since bicuculline is considered to be a specific antagonist of $\operatorname{GABA}(6,7)$.

Chlorpromazine produced no direct depressant effect on the firing of Purkinje cells, which were sensitive to both IAA and glycine, nor any synergistic action with IAA and glycine. These data provide further evidence that chlorpromazine does not act on the GABA-operated synapses and does not affect glycine-sensitive neurons.

\section{REFERENCES}

1) Marlyama, S. and Kawasaki, T, Japan. J. Pharmacol. 25, 209 (1975); 2) Godfraind, J.M., Krnjevié, K., Maretić, H. and Pumain, R.: Canad. J. Physiol. Pharmacol. 51, 790 (1973); 3) HaAs, H.l., Andfrson, E.G. and Hösli, L.: Brain Res. 51, 269 (1973); 4) Constantt, A. and Quilliam, J.P.: Brain Res. 79, 306 (1974); 5) Kawamura, H. And Provini, L.: Brain Res. 24, $293(1970)$; 6) Curtis, D.R., Duggan, A.W., Fllix, D., Johnston, G.A.R. And Mclennan, H.: Brain Res. 33, 57 (1971); 7) Curtis, D.R. And Fetix, D.: Brain Res. 34, 301 (1971) 